\title{
Gerakan Masyarakat Hidup Sehat Mencuci Tangan Sebagai Upaya untuk Menerapkan Perilaku Hidup Bersih dan Sehat Sejak Dini di Kabupaten Blora
}

\author{
Dina Dewi Anggraini ${ }^{1}$, Marlynda Happy Nurmalita Sari ${ }^{2}$ \\ ${ }^{1,2}$ Poltekkes Kemenkes Semarang \\ Email korespondensi: dewidina90@gmail.com
}

\begin{abstract}
Abstrak
Pelaksanaan pembangunan dalam bidang kesehatan memberikan prioritas pada upaya peningkatan kesehatan, pencegahan penyakit dengan tidak mengabaikan upaya penyembuhan dan pemulihan kesehatan, termasuk kepada anak usia Sekolah Dasar demi tercapainya derajat kesehatan yang optimal. Adapaun usaha untuk menunjang kesehatan yang optimal maka dilakukan upaya di bidang kesehatan yaitu kebiasaan mencuci tangan sebelum dan sesudah makan perlu mendapat perhatian. Pengabdian ini dilakukan di Kabupaten Blora dengan sasaran yaitu perwakilan siswa kelas 1 Sekolah Dasar di Kota Blora, dan bersedia mengikuti kegiatan secara penuh. Sasaran yang diikutsertakan sejumlah 40 perwakilan dari siswa kelas 1 Sekolah Dasar yang ada di Kota Blora, yaitu SDN 1 Karangjati, SDN 2 Karangjati, SDN 4 Karangjati, dan SDN Kedung Jenar. Tujuan dari pengabdian masyarakat ini yaitu untuk meningkatkan pengetahuan dan keterampilan anak Sekolah Dasar dalam hal personal hygiene khususnya cuci tangan dengan langkah yang benar dan bisa menjadikan kebiasaan perilaku hidup sehari-hari sehingga dapat menurunkan angka morbiditas dan menyiapkan para generasi penerus bangsa yang sehat serta berkualitas. Metode kegiatan pengabdian masyarakat yang digunakan yaitu metode ceramah, demonstrasi dan mempraktikkan langsung. Hasil kegiatan ini adalah peningkatan pengetahuan dan keterampilan pada siswa kelas 1 Sekolah Dasar tentang cuci tangan dengan langkah yang benar dan menggunakan sabun serta air mengalir.
\end{abstract}

Kata kunci: Personal hygiene, cuci tangan, pengetahuan, keterampilan

\begin{abstract}
Implementation of development in the health sector by giving priority to efforts to improve health, prevention of disease by not ignoring efforts to heal and restore health, including elementary school age children in order to achieve optimal health. As for efforts to support optimal health efforts, efforts are made in the health sector, namely the habit of washing hands before and after eating, need attention. Community service is carried out in Blora Regency with the target of representing representatives of grade 1 students of elementary schools in the City of Blora, and willing to participate in full activities. The targets included 40 representatives from grade 1 students in Blora City, namely SDN 1 Karangjati, SDN 2 Karangjati, SDN 4 Karangjati, and SDN Kedung Jenar. The purpose of this community service is to improve the knowledge and skills of elementary school children in terms of personal hygiene, especially washing their hands with the right steps and can make the habits of daily living behavior so as to reduce morbidity and prepare the next generation of healthy and quality nation. The method of community service activities used is the method of lectures, demonstrations and direct practice. The result of this activity was an increase in knowledge and skills in grade 1 elementary school students about washing hands with the right steps and using soap and running water.
\end{abstract}

Keywords: Personal hygiene, hand washing, knowledge, skills

Jurnal Pengabdian Masyarakat Al-Irsyad Vol. II, No. 1. April 2020 


\section{PENDAHULUAN}

Gerakan Masyarakat Hidup Sehat (GERMAS) adalah gerakan nasional yang diprakarsai oleh Presiden Negara Republik Indonesia dalam mengoptimalkan upaya promotif dan upaya preventif tanpa mengesampingkan upaya kuratif dan upaya rehabilitatif sebagai payung besar tercapainya kehidupan yang sehat, dan menurunkan prevalensi dari penyakit (Kemenkes, 2016).

Pelaksanaan pembangunan dalam bidang kesehatan dengan memberikan prioritas pada upaya peningkatan kesehatan, pencegahan penyakit dengan tidak mengabaikan upaya penyembuhan dan pemulihan kesehatan, termasuk kepada anak usia Sekolah Dasar demi tercapainya derajat kesehatan yang optimal. Adapaun usaha untuk menunjang upaya kesehatan yang optimal maka upaya di bidang kesehatan yaitu kebiasaan mencuci tangan sebelum dan sesudah makan perlu mendapat perhatian (Rismawati, 2012).

Menurut Notoatmodjo (2014), pengertian dari media promosi kesehatan yaitu semua sarana atau upaya untuk menampilkan pesan atau informasi yang tersedia yang disampaikan oleh komunikator, baik itu melalui media cetak, elektronik dan media di luar ruang. Sehingga sasaran dapat meningkatkan pengetahuan dan keterampilan yang akhirnya diharapkan dapat menciptakan perubahan perilaku dalam kehidupan sehari-hari ke arah yang positif atau lebih baik.

Perilaku hidup bersih sehat pada dasarnya merupakan sebuah upaya untuk menularkan pengalaman mengenai pola hidup sehat melalui individu, kelompok ataupun masyarakat luas dengan jalur-jalur komunikasi sebagai media berbagi informasi. Ada berbagai informasi yang dapat dibagikan seperti materi edukasi guna menambah pengetahuan serta meningkatkan sikap dan perilaku terkait cara hidup yang bersih dan sehat (Departemen Kesehatan RI, 2005).

Personal hygiene merupakan perawatan diri sendiri yang dilakukan untuk mempertahankan kesehatan baik secara fisik maupun psikologis (Ambarwati dkk, 2009). Salah satu cara personal hygiene yaitu dengan mencuci tangan menggunakan sabun dan air mengalir (Siswanto, 2010).

Mencuci tangan dengan menggunakan sabun terbukti secara ilmiah efektif untuk mencegah penyebaran penyakit-penyakit menular seperti diare, Infeksi Saluran Pernapasan Atas (ISPA) dan Flu Burung. Sebagaimana diketahui bahwa 
mencuci tangan dalam kehidupan sehari-hari sangat penting, contohnya setelah buang air dan sebelum memegang makanan. Cuci tangan sangat berperan dalam membantu mengurangi risiko terkena diare lebih dari $40 \%$ dan infeksi saluran pernapasan hampir 25\%(Depkes, 2010).

Masih banyak gangguan kesehatan yang diderita seseorang seperti diare, infeksi kulit, gangguan pada kesehatan gigi dan mulut karena tidak terpeliharanya kebersihan perorangan dengan baik. Puluhan penyakit yang ditularkan lewat tangan yang kotor bisa dicegah dengan cuci tangan dengan sabun. Kemauan anak dalam cuci tangan dipengaruhi oleh faktor-faktor citra diri, status sosial dan ekonomi, pengetahuan, kebiasaan anak, sikap, motivasi, pola asuh orang tua dan peran guru di sekolah (Handrawan Nadesul, 2007). Dampak jangka pendek yang bisa ditimbulkan jika tidak menjaga kebersihan tangan adalah mudah tertular penyakit seperti diare, kolera, penyakit kulit, dan infeksi, sedangkan jangka panjang akan mempengaruhi pola hidup bersih dan sehat (Komarudin, 2009).

Dalam penelitian yang dilakukan oleh Agus (2020), bahwa kesadaran masyarakat Indonesia untuk mencuci tangan memakai sabun terbukti masih rendah. Dan hal ini terlihat juga pada hasil Riset Kesehatan Dasar tahun 2013 yaitu pada proporsi penduduk umur di bawah 10 tahun yang berperilaku mencuci tangan dengan benar tercatat $47 \%$. Kegiatan mencuci tangan dengan sabun dan air mengalir merupakan salah satu cara yang efektif untuk mencegah penyakit diare dan terbukti dari beberapa riset menunjukkan ada hubungan yang signifikan antara perilaku mencuci tangan dengan menggunakan sabun dan air mengalir pada siswa Sekolah Dasar dengan kejadian diare.

Berdasarkan penelitian yang dilakukan oleh Hariyadi tahun 2015 di SDN Segulung 02 Kecamatan Dagangan Kabupaten Madiun bahwa hasil survey melalui wawancara dengan 10 siswa mengatakan belum mengetahui teknik mencuci tangan dengan baik dan benar. Siswa mengatakan belum diberikan pendidikan kesehatan tentang langkah mencuci tangan pakai sabun. Siswa diberikan pendidikan kesehatan secara umum saja seperti kebersihan kelas dan lingkungan sekolah. Dan setelah dilakukan pemberian pendidikan kesehatan degan metode ceramah serta demonstrasi, menyebabkan terjadinya peningkatan pengetahuan siswa tentang cuci 
tangan pakai sabun yaitu dari 66,56 dengan kategori cukup menjadi 97,19 dengan kategori sangat baik.

Tujuan dari gerakan masyarakat hidup sehat yang dilakukan ini yaitu untuk meningkatkan pengetahuan dan keterampilan anak Sekolah Dasar dalam hal personal hygiene mencuci tangan. Dengan sosialisasi ini, diharapkan bisa memberi perubahan perilaku yang lebih baik kepada anak dalam melakukan personal hygiene mencuci tangan dengan benar.

Hal ini mendorong Prodi DIII Kebidanan Blora Poltekkes Kemenkes Semarang untuk melaksanakan kegiatan Pengabdian kepada Masyarakat (Pengabdian masyarakat) berupa Gerakan Masyarakat Hidup Sehat Mencuci Tangan Sebagai Upaya untuk Menerapkan Perilaku Hidup Bersih dan Sehat Sejak Dini di Kabupaten Blora, sebagai bentuk dukungan terhadap program pemerintah di bidang kesehatan dan perwujudan Tri Dharma Perguruan Tinggi.

\section{MASALAH}

Berdasarkan hal tersebut, permasalahan yang ada pada mitra antara lain :

1) Kurangnya pengetahuan pada siswa Sekolah Dasar terkait personal hygiene khususnya cuci tangan dengan langkah yang benar

2) Kurangnya keterampilan pada siswa Sekolah Dasar terkait melakukan langkah cuci tangan dengan benar yang menjadikan kebiasaan perilaku hidup sehari-hari sehingga dapat menurunkan angka morbiditas dan menyiapkan para generasi penerus bangsa yang sehat serta berkualitas

\section{METODE}

Pengabdian kepada masyarakat ini dilaksanakan di Kabupaten Blora. Sasaran pengabdian masyarakat Prodi DIII Kebidanan Blora adalah perwakilan siswa kelas

1 Sekolah Dasar di Kota Blora, dan bersedia mengikuti kegiatan "Gerakan Masyarakat Hidup Sehat Mencuci Tangan Sebagai Upaya untuk Menerapkan Perilaku Hidup Bersih dan Sehat Sejak Dini” secara penuh. Sasaran yang akan diikut sertakan sejumlah 40 perwakilan dari siswa kelas 1 Sekolah Dasar yang ada di Kota Blora, yaitu SDN 1 Karangjati, SDN 2 Karangjati, SDN 4 Karangjati, dan SDN Kedung Jenar. Adapun metode pengabdian kepada masyarakat ini adalah : 
1) Alur kegiatan

a. Persiapan peralatan

b. Koordinasi dengan Kepala Sekolah Dasar di Kota Blora untuk perwakilan kepesertaan kegiatan pengadian masyarakat

c. Pelaksanaan kegiatan pengabdian masyarakat

d. Evaluasi

2) Tahapan kegiatan

Kegiatan pengabdian masyarakat ini dilaksanakan dengan rincian sebagai berikut :

a. Senam bersama

b. Pre test

c. Pemberian materi dengan ceramah terkait perilaku hidup bersih dan sehat

d. Demonstrasi mencuci tangan dengan menggunakan sabun dan air mengalir

e. Mencuci tangan dengan menggunakan sabun dan air mengalir sebelum makan buah

f. Makan buah bersama

g. Mencuci tangan dengan menggunakan air mengalir dan sabun sesudah makan buah

h. Post test dan evaluasi

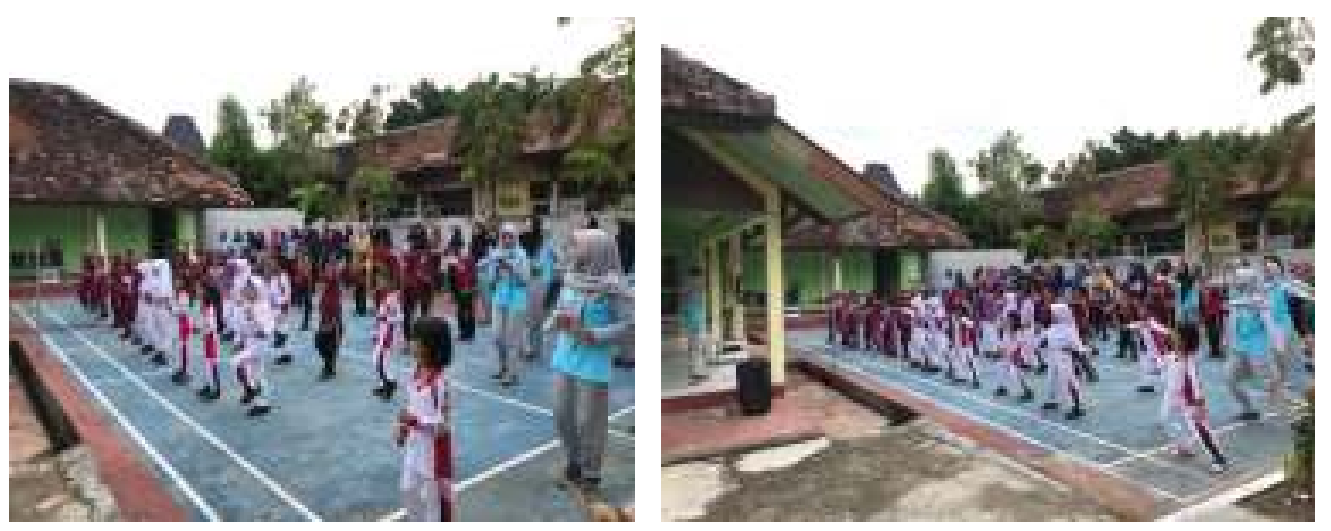

Gambar 1. Kegiatan Senam Bersama

3) Intervensi yang dilakukan

Intervensi yang dilakukan dengan pemberian materi menggunakan metode ceramah, demonstrasi dan mempraktikkan langsung. Materi tersebut diberikan dengan suasana yang menyenangkan dengan komunikasi dua arah kepada peserta kegiatan pengabdian masyarakat. 


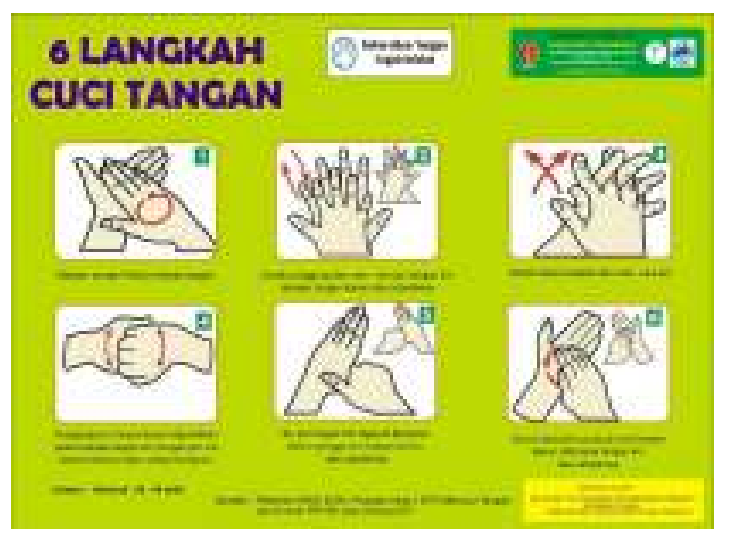

Gambar 2. Teknik Cuci Tangan dengan Menggunakan Air dan Sabun (WHO, 2009)

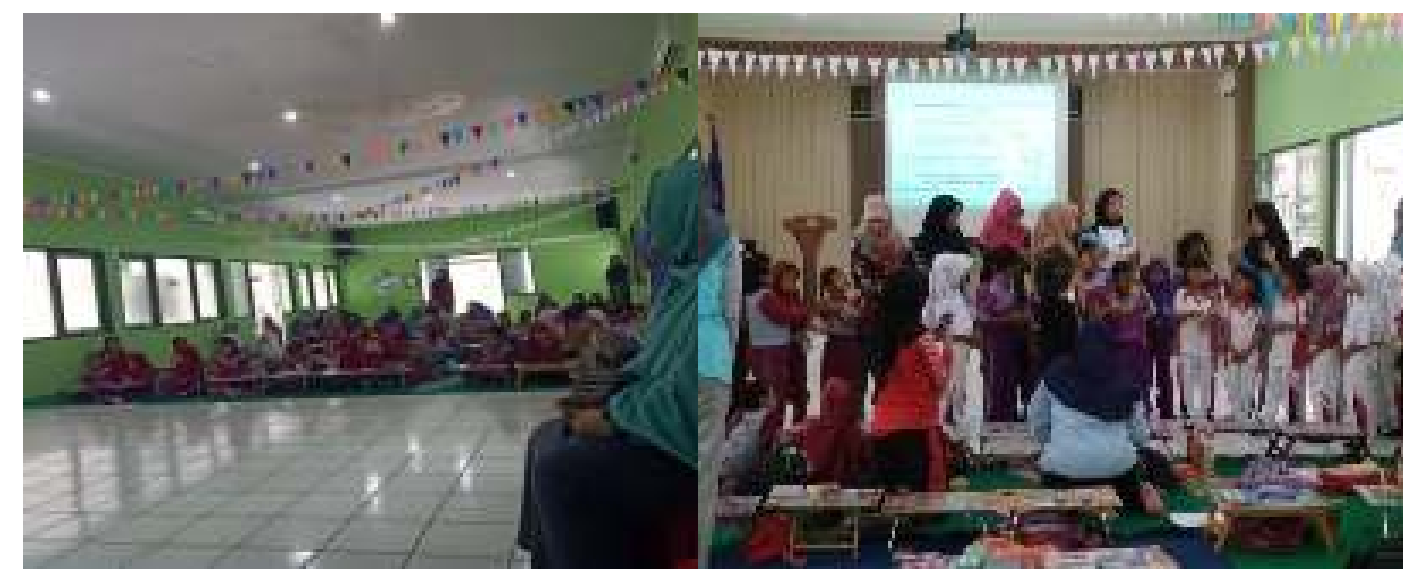

Gambar 3. Sikap Siswa Ketika Pemberian Materi dengan Metode Ceramah dan Demonstrasi 6 Langkah Cuci Tangan dengan Benar

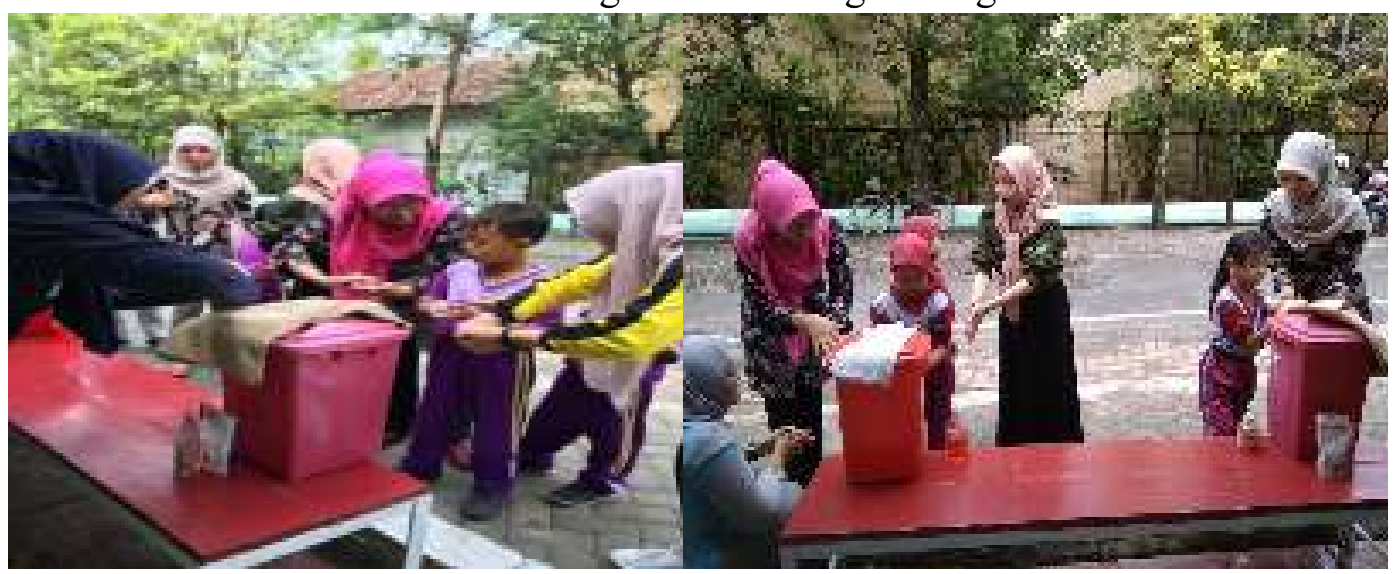

Gambar 4. Praktik Langsung 6 Langkah Cuci Tangan dengan Sabun

4) Evaluasi yang dilakukan

Evaluasi dalam kegiatan ini yaitu tanya jawab dengan siswa Sekolah Dasar setelah diberikan post test diakhir kegiatan. Diharapkan dengan adanya kegiatan ceramah, demonstrasi dan praktik langsung mencuci tangan dengan sabun dan air mengalir bisa meningkatkan pengetahuan, keterampilan, menanamkan jiwa bersih 
dan sehat, serta pada akhirnya bisa menjadikan pola kebiasaan dalam kehidupan sehari-hari pada siswa Sekolah Dasar.

\section{HASIL DAN PEMBAHASAN}

\section{1) Hasil}

Pelaksanaan program pengabdian masyarakat Prodi DIII Kebidanan Blora Poltekkes Kemenkes Semarang, dilaksanakan di Kota Blora pada hari Jum'at, 1 November 2019 berjalan dengan baik dan lancar. Pengabdian masyarakat ini diikuti oleh perwakilan siswa kelas 1 yang berasal dari SDN 1 Karangjati, SDN 2 Karangjati, SDN 4 Karangjati dan SDN Kedung Jenar.

Program pengabdian ini berupa pemberian materi dengan metode ceramah, dan demonstrasi tentang personal hygiene yang berupa cuci tangan menggunakan sabun dan air mengalir sesuai dengan yang telah disampaikan sebelumnya. Pada tahap pelaksanaan digunakan empat metode, yaitu metode ceramah, tanya jawab, demonstrasi, dan praktik langsung. Metode ceramah bertujuan memberikan pengetahuan terkait dengan personal hygiene, tujuan mencuci tangan, manfaat mencuci tangan, indikasi waktu mencuci tangan, dan teknik mencuci tangan yang efektif yaitu 6 langkah cuci tangan memakai sabun dan air mengalir. Metode tanya jawab bertujuan mengetahui penguasaan materi yang telah disampaikan melalui ingatan dan pengungkapan perasaan serta sikap siswa tentang yang dipelajari, dan didengar terkait dengan personal hygiene, tujuan mencuci tangan, manfaat mencuci tangan, indikasi waktu mencuci tangan, dan teknik mencuci tangan yang efektif yaitu 6 langkah cuci tangan memakai sabun dan air mengalir. Metode demonstrasi bertujuan memberikan pengalaman belajar melalui perbuatan melihat dan mendengarkan diikuti dengan meniru pekerjaan yang didemonstrasikan terkait dengan 6 langkah cuci tangan memakai sabun dan air mengalir. Metode praktik bertujuan memberikan kesempatan berlatih kepada siswa untuk meningkatkan ketrampilan sebagai penerapan bahan/pengetahuan yang telah dipelajari sebelumnya mencapai tujuan dari pengajaran yang telah disampaikan, yaitu praktik 6 langkah cuci tangan memakai sabun dan air mengalir.

Untuk itu tujuan dari pengabdian kepada masyarakat yang dilakukan Prodi DIII Kebidanan Blora yaitu untuk meningkatkan pengetahuan dan keterampilan 
anak Sekolah Dasar dalam hal personal hygiene mencuci tangan menggunakan sabun dan air mengalir. Dengan sosialisasi melalui kegiatan pengabdian kepada masyarakat ini, diharapkan bisa memberi perubahan perilaku yang lebih baik kepada anak dalam melakukan personal hygienemencuci tangan dengan benar.

Berikut karakteristik peserta kegiatan pengabdian masyarakat berjudul Gerakan Masyarakat Hidup Sehat Mencuci Tangan Sebagai Upaya untuk Menerapkan Perilaku Hidup Bersih dan Sehat Sejak Dinidi Kabupaten Blora :

a. Karakteristik peserta kegiatan pengabdian masyarakat berdasarkan umur

Tabel 1. Karakteristik peserta kegiatan pengabdian masyarakat berdasarkan umur

\begin{tabular}{llcc}
\hline Variabel & & f & \% \\
\hline Umur & 6 th & 10 & 25 \\
& 7 th & 25 & 62.5 \\
& $>7$ th & 5 & 12.5 \\
\hline & Jumlah & 40 & 100 \\
\hline
\end{tabular}

Sumber : Data Primer, 2019

Pada tabel 1. menunjukan bahwa umur paling banyak pada responden adalah 7 tahun sebanyak $62.5 \%$, sedangkan untuk umur terendah adalah $>7$ tahun sebanyak $12.5 \%$.

b. Pengetahuan peserta kegiatan pengabdian masyarakat sebelum dan sesudah diberikan materi dengan metode ceramah

Tabel 2. Pengetahuan peserta kegiatan pengabdian masyarakat sebelum dan sesudah diberikan materi dengan metode ceramah

\begin{tabular}{ccccc}
\hline \multirow{2}{*}{ Pengetahuan } & \multicolumn{2}{c}{ Sebelum } & $\mathbf{f}$ & Sesudah \\
\cline { 2 - 5 } & $\mathbf{f}$ & 10 & 23 & 57.5 \\
Baik & 4 & 35 & 14 & 35 \\
Cukup & 14 & 55 & 3 & 7.5 \\
Kurang & 22 & 100 & 40 & 100 \\
\hline Jumlah & 40 & & &
\end{tabular}

Sumber : Data Primer, 2019

Pada tabel 2. diatas menunjukkan bahwa pengetahuan baik pada sebelum pelatihan adalah $10 \%$ sedangkan setelah pelatihan adalah $57.5 \%$.

c. Praktik peserta kegiatan pengabdian masyarakat sebelum dan sesudah demonstrasi

Tabel 3. Praktik peserta kegiatan pengabdian masyarakat sebelum dan sesudah demonstrasi

\begin{tabular}{cccccc}
\hline \multirow{2}{*}{ Praktek } & \multicolumn{2}{c}{ Sebelum } & \multicolumn{3}{c}{ Sesudah } \\
\cline { 2 - 6 } & & $\mathbf{f}$ & $\mathbf{\%}$ & $\mathbf{f}$ & $\mathbf{\%}$ \\
\hline Baik & 6 & 15 & 31 & 77.5 \\
Kurang & 34 & 85 & 9 & 22.5 \\
\hline Jumlah & 40 & 100 & 40 & 100 \\
\hline Sumber: Data Primer, 2019 & & &
\end{tabular}


Pada tabel 3. diatas menunjukkan praktik peserta kegiatan pengabdian masyarakat sebelum dan sesudah demonstrasi adalah baik sebanyak $15 \%$ menjadi $77.5 \%$

d. Uji beda pengetahuan dan praktik sebelum dan sesudah pemberian materi dengan metode ceramah serta demonstrasi

Tabel 4. Uji beda pengetahuan dan praktik sebelum dan sesudah pemberian materi dengan metode ceramah serta demonstrasi

\begin{tabular}{llccc}
\hline Variabel & & Mean & n & p \\
\hline Pengetahuan & Sebelum pemberian materi & 56.0 & 40 & 0.000 \\
& Sesudahpemberian materi & 77.0 & 40 & \\
Praktik & Sebelum demonstrasi & 47.91 & 40 & 0.000 \\
& Sesudah demonstrasi & 78.74 & 40 & \\
\hline
\end{tabular}

Sumber : Data Primer, 2019

Berdasarkan tabel diatas menggunakan uji paired t-test menunjukkan bahwa ada perbedaan pengetahuan peserta kegiatan pengabdian masyarakat sebelum dan sesudah diberikan materi melaui metode ceramah dengan nilai signifikan $p=0.000$ $(\mathrm{p}<0.05)$ dan ada perbedaan praktik peserta kegiatan pengabdian masyarakat sebelum dan sesudah demonstrasi dengan nilai signifikan $\mathrm{p}=0.000(\mathrm{p}<0.05)$.

\section{2) Pembahasan}

Persyaratan umur siswa kelas 1 Sekolah Dasar yaitu telah berumur 7 sampai dengan 12 tahun wajib diterima, dan umur yang paling rendah yaitu umur 6 tahun (Dadang, 2015).

Menurut Kementerian Pendidikan dan Kebudayaan (Kemendikbud), anak yang masuk ke Sekolah Dasar sebaiknya pada umur 7 tahun. Ada 4 aspek yang menjadi pertimbangan Kemendikbud dalam menetapkan umur tersebut sebagai umur yang sesuai bagi anak untuk bersekolah. 4 aspek tersebut adalah : (1) Aspek fisik yaitu memiliki otot dan saraf yang telah terbentuk, juga gerakan motorik yang lebih baik. Oleh karena itu, mereka sudah mampu untuk bertahan di dalam kelas dari pagi hingga siang dan mengikuti pelajaran yang diberikan. Mereka pun bisa menggunakan alat tulis sendiri tanpa dibantu. (2) Aspek psikologis yaitu kemampuan konsentrasi sudah meningkat, dengan rentang konsentrasi sekitar 3045 menit. Jadi, mereka mampu memilih dan membedakan hal-hal mana yang harus diperhatikan dan mana yang tidak. (3) Aspek kognitif yaitu mampu memahami dan mengikuti instruksi yang diberikan dalam mengerjakan tugas-tugas. (4) Aspek emosi yaitu emosi anak sudah berada pada tahap yang lebih matang. Dengan begitu, 
mereka lebih bisa mandiri, membedakan waktu belajar dan bermain, serta mampu mengerjakan tugas yang diberikan (Andrea, 2019). Umur peserta kegiatan pengabdian masyarakat adalah paling banyak pada responden adalah 7 tahun, sedangkan untuk umur terendah adaalah $>7$ tahun.

Pengetahuan seseorang bisa menjadi lebih luas dengan memiliki sumber informasi yang lebih banyak, seseorang akan cenderung untuk mendapatkan informasi, baik dari orang lain maupun dari media massa. Semakin banyak pengetahuan yang dimiliki maka akan mempengaruhi praktik siswa Sekolah Dasar. Demikian sebaliknya apabila peserta kegiatan pengabdian masyarakat memiliki pengetahuan yang rendah, akan menghambat perkembangan praktik dalam memperoleh informasi baru (Wawan dan Dewi, 2010).

Pendidikan kesehatan melalui pemberian materi tentang kesehatan merupakan upaya untuk mempengaruhi dan mengajak orang lain baik individu, kelompok, atau masyarakat agar melaksanakan perilaku hidup sehat. Diharapkan melalui pemberian materi terkait dengan personal hygiene yaitu tujuan mencuci tangan, manfaat mencuci tangan, indikasi waktu mencuci tangan, dan teknik mencuci tangan yang efektif yaitu 6 langkah cuci tangan memakai sabun dan air mengalir dapat mengubah perilaku siswa Sekolah Dasar dari perilaku yang negatif mengarah ke perilaku yang positif. Untuk mencapai perilaku positif terdapat beberapa faktor yang mempengaruhi proses perubahan tersebut, sesuai dengan teori Green (1980) dalam Notoatmodjo, 2012, yaitu predisposing factors, enabling factors, dan reinforcing factors. Selain itu sesuai dengan teori Rogers (1995) dalam Notoatmodjo (2012), proses perubahan perilaku juga didahului oleh perubahan pengetahuan, perubahan sikap atau persuasi, pengambilan keputusan, sehingga pada akhirnya akan tercapai tahap implementasi dan konfirmasi.

Dari hasil analisis data tentang kegiatan pengabdian masyarakat didapatkan bahwa pengetahuan dan praktik peserta kegiatan pengabdian masyarakat mengalami peningkatan setelah mendapatkan materi menggunakan metode ceramah dan demonstrasi. Hal tersebut menunjukkan adanya pengaruh yang signifikan berupa peningkatan pengetahuan dan praktik peserta kegiatan pengabdian masyarakat. Sebelum diberikan dengan metode ceramah dan demonstrasi cuci tangan sebagian besar peserta berpengetahuan dan berketrampilan 
kurang, setelah dilakukan intervensi dan implementasi dalam bentuk ceramah dan demonstrasi terjadi peningkatan pengetahuan yang sangat signifikan, begitu juga dengan praktik siswa Sekolah Dasar dalam kegiatan cuci tangan dengan menggunakan sabun dan air mengalir.

Pengetahuan peserta sebagian besar setelah dilakukan kegiatan pengabdian masyarakat yaitu pengetahuan peserta menjadi pengetahuan baik. Hal ini sejalan dengan penelitian Hidayati, Salawati dan Istiana (2015) yang menyatakan bahwa metode demonstrasi lebih mudah untuk menunjukkan pengertian, ide, dan prosedur tentang suatu hal yang pernah dipersiapkan dengan teliti untuk memperlihatkan bagaimana cara melaksanakan suatu tindakan adegan dengan menggunakan alat peraga.

Praktik siswa Sekolah Dasar mengalami peningkatan dari kurang menjadi baik setelah dilakukan demonstrasi. Dengan dilakukan pemberian materi terkait dengan personal hygiene, tujuan mencuci tangan, manfaat mencuci tangan, indikasi waktu mencuci tangan, dan demonstrasi teknik mencuci tangan yang efektif yaitu 6 langkah cuci tangan memakai sabun dan air mengalir diharapkan siswa Sekolah Dasar memahami tujuan dari pemberianmateri yaitu siswa Sekolah Dasar mampu memahami dan praktik tentang cara mencuci tangan dengan benar sehingga dapat menjadikannya sebagai perilaku dalam kehidupan sehari-hari.

\section{KESIMPULAN}

Beberapa kesimpulan yang didapatkan dari kegiatan pengabdian masyarakat tentang gerakan masyarakat hidup sehat mencuci tangan sebagai upaya untuk menerapkan perilaku hidup bersih dan sehat sejak dini di Kabupaten Blora yaitu :

1) Ada peningkatan pengetahuan pada siswa kelas 1 Sekolah Dasar tentang personal hygiene yaitu cuci tangan.

2) Ada peningkatan keterampilan cuci tangan menggunakan sabun dan air mengalir pada siswa kelas 1 Sekolah Dasar.

\section{DAFTAR PUSTAKA}

Agus Erwin Ashari. Peningkatan Pengetahuan, Sikap dan Praktik Cuci Tangan Pakai Sabun pada Anak Kelas V Sekolah Dasar Melalui Senam Cuci Tangan 
Pakai Sabun. Jurnal Ilmiah Permas : Jurnal Ilmiah Stikes Kendal . Vol 10 No 1 (2020).

Alimul H. A, Aziz, 2005. Pengantar Ilmu Keperawatan Anak I. Buku 1. Jakarta: Salemba Medika.

Ambarwati, Eny dkk. 2009. KDPK Kebidanan Teori dan Aplikasi. Jogjakarta : Nuha Medika.

Dadang. 2015. Dasar Hukum Umur/Usia Peserta Didik Baru Kelas 1 SD/MI Minimal 6 Tahun Dapat Diterima. https://www.dadangjsn.com/2015/08/dasar-hukum-umur-usia-pesertadidik.html

Departemen Kesehatan RI. 2005. Perilaku Hidup Bersih dan Sehat di Indonesia. Jakarta.

Dewi dan Wawan. 2010. Teori Pengukuran Pengetahuan Sikap dan Perilaku Manusia. Yogyakarta: Nuha Medika.

Dinkes Jawa Tengah. 2010.Pedoman Perilaku Hidup Bersih dan Sehat (PHBS) di Institusi. Semarang.

Hariyadi. 2015. Pengaruh Pendidikan Kesehatan tentang Cuci Tangan Pakai Sabun dengan Metode Ceramah dan Demonstrasi Terhadap Pengetahuan Mencuci Tangan pada Siswa di SDN Segulang 02 dan SDN Segulang 05 Desa Segulang Kecamatan Dagangan Kabupaten Madiun. Artikel Stikes Bhakti Husada Mulia Madiun.

Hidayati, A, Salawati, T, dan Istiana, S. 2012. Pengaruh Pendidikan Kesehatan Melalui Metode Ceramah dan Demonstrasi Dalam Meningkatkan Pengetahuan Tentang Kanker Payudara dan Ketrampilan Praktik SADARI. Jurnal Kebidanan Vol. 1 No. 1. Februari 2013.

Kemenkes RI. 2010. Pedoman perilaku hiudp bersih dan sehat. Jakarta : Kementrian Kesehatan Republik Indonesia.

Kemenkes RI. 2013. Riset Kesehatan Dasar 2012. Jakarta : Kemenkes RI.

Kemenkes RI. 2017. Profil Kesehatan Indonesia 2016. Jakarta : Keputusan Menteri Kesehatan Republik Indonesia.

Lidwina, Andrea. 2019. Mengapa Usia Anak Masuk SD Harus 7 Tahun?. https://blog.ruangguru.com/mengapa-usia-anak-masuk-sd-harus-7-tahun

Notoatmodjo, S. 2012. Pendidikan dan Perilaku Kesehatan. Jakarta:PT Rineka Cipta. 
Notoatmodjo, S. 2014. Ilmu Perilaku Kesehatan. Jakarta : Rineka Cipta.

Siswanto, Hadi, 2010. Pendidikan Kesehatan Anak Usia Dini. Yogyakarta: Pustaka Rihama.

Sunarsih.2011. KDPK kebidanan teori dan aplikasi.jogjakarta : Nuha Medika.

WHO. 2009. Guidelines on Hand Hygiene in Health Care. WHO Press. Geneva. 